University of Nebraska - Lincoln

DigitalCommons@University of Nebraska - Lincoln

$5-29-2019$

\title{
Seasonal Dynamics of Lipid Metabolism and Energy Storage in the Brazilian Free-Tailed Bat
}

\author{
Elizabeth J. Rogers \\ Texas Tech University, elizabeth.j.rogers@ttu.edu \\ Amie S. Sommers \\ Texas Tech University \& University of Nebraska-Lincoln,, asommers2@unl.edu \\ Liam P. McGuire \\ Texas Tech University, liam.mcguire@ttu.edu
}

Follow this and additional works at: https://digitalcommons.unl.edu/natrespapers

Part of the Natural Resources and Conservation Commons, Natural Resources Management and Policy Commons, and the Other Environmental Sciences Commons

Rogers, Elizabeth J.; Sommers, Amie S.; and McGuire, Liam P., "Seasonal Dynamics of Lipid Metabolism and Energy Storage in the Brazilian Free-Tailed Bat" (2019). Papers in Natural Resources. 1119. https://digitalcommons.unl.edu/natrespapers/1119

This Article is brought to you for free and open access by the Natural Resources, School of at DigitalCommons@University of Nebraska - Lincoln. It has been accepted for inclusion in Papers in Natural Resources by an authorized administrator of DigitalCommons@University of Nebraska - Lincoln. 


\section{Seasonal Dynamics of Lipid Metabolism and Energy Storage in the Brazilian Free-Tailed Bat}

\author{
Elizabeth J. Rogers ${ }^{1, \star}$ \\ Amie S. Sommers ${ }^{1,2, \dagger}$ \\ Liam P. McGuire ${ }^{1, \ddagger}$ \\ ${ }^{1}$ Department of Biological Sciences, Texas Tech University, \\ 2901 Main Street, Lubbock, Texas 79409; ${ }^{2}$ School of Natural \\ Resources, University of Nebraska-Lincoln, 3310 Holdrege \\ Street, Lincoln, Nebraska 68583
}

Accepted 4/20/2019; Electronically Published 5/29/2019

\begin{abstract}
As small, flying, mammalian endotherms, insectivorous bats are adapted to operate at high levels of energy expenditure. In response to seasonally variable challenges, we predicted that bats should balance energy budgets by flexibly adjusting aspects of their physiology or behavior in ways that elevate metabolic capacity. We examined variation in energy storage and pathways for oxidative metabolism in Brazilian free-tailed bats ( $\mathrm{Ta}$ darida brasiliensis) related to estimated costs associated with reproduction and migration. We collected pectoral muscle and liver from female $T$. brasiliensis at six time points during the summer and fall and measured changes in the activity of four enzymes involved with lipid metabolism. Body mass varied substantially with life-cycle stage, suggesting that rapid accumulation and use of fat stores occurs in response to current and anticipated energy demands. Catabolic enzyme activity (carnitine palmitoyl transferase [CPT], 3-hydroxyacyl-CoA dehydrogenase [HOAD], and citrate synthase [CS]) in the muscle was increased during lactation compared with early pregnancy but exhibited no change before fall migration. While there was no temporal change in lipid biosynthetic capacity in the liver, fatty acid synthase activity was negatively correlated with body mass. Variation in body mass and enzyme activity in T. brasiliensis during the summer suggests that stored energy is mobilized and lipid oxidative capacity is increased during periods of increased demand and that lipid biosynthetic capacity is increased with depletion of fat stores. These results suggest that bats are able to flexibly adjust metabolic capacity based on energy requirement to maintain energy balance despite high levels of expenditure.
\end{abstract}

*Email: elizabeth.j.rogers@ttu.edu.

$\dagger$ Email: amie.sommers@ttu.edu.

¥Corresponding author; email: liam.mcguire@ttu.edu.

Physiological and Biochemical Zoology 92(4):386-395. 2019. (C) 2019 by The University of Chicago. All rights reserved. 1522-2152/2019/9204-8111\$15.00. DOI: $10.1086 / 704107$
Keywords: lipid oxidation, energy trade-offs, muscle physiology, reproduction, migration, bats.

\section{Introduction}

Energy metabolism is constrained in all animals by limits on intake capacity and maximal rates of energy expenditure (Levins 1968; Speakman 1999). This universal generalization drives trade-offs in the allocation of limited energy resources to major life functions, leading to the evolution of physiological or behavioral adaptations that allow animals to meet metabolic requirements while maximizing fitness (Stearns 1989; Weiner 1992; Zera and Harshman 2001; Ricklefs and Wikelski 2002; Garland 2014). When animals operate at intensities approaching maximum metabolic capacity, the physiological machinery used to assimilate, process, and allocate energy can limit performance by introducing bottlenecks that constrain the rate at which nutrients are supplied to cells and converted into chemical energy for tissue growth or work (Hammond and Diamond 1997). To balance energy budgets in response to challenges that require elevated expenditure, animals can increase energy intake, decrease allocation of energy to nonessential physiological functions, or make physiological adjustments that increase metabolic capacity in tissues requiring elevated output (Karasov 1986; Speakman 2008). For example, migratory birds fuel highintensity flights via both physiological trade-offs, such as decreased investment in immune function (reviewed in Buehler and Piersma 2008), and increased capacity for fatty acid oxidation (Guglielmo et al. 2002; McWilliams et al. 2004).

For animals that experience complex life histories or unpredictable ecological pressures throughout the annual cycle, the ability to continuously and reversibly adjust their physiology, behavior, or morphology in response to challenges posed by environmental condition or life-history stage may obtain a selective advantage (Piersma and Drent 2003). Phenotypic flexibility, the term used to describe these reversible within-individual phenotypic changes, allows animals to maximize their performance under a wide range of conditions and potentially avoid the need for other functional trade-offs (Piersma and van Gils 2011). Highly aerobic animals in particular may benefit from physiological mechanisms that allow elevated metabolic capacity in situations of energetic constraint while limiting the cost of maintaining excess capacity when in energy balance.

Bats are an appropriate system for addressing the dynamics of energy metabolism through the annual cycle because they are adapted for high rates of energy expenditure (Thomas and 
Suthers 1972; Speakman and Thomas 2003). Flapping flight is the most costly mode of locomotion per unit time and is considerably more energetically costly than forms of terrestrial locomotion (Schmidt-Nielsen 1972). Flying bats expend energy at about 16.5 times basal metabolic rate (Speakman and Thomas 2003), and although no specific estimates are available for bats, there is no difference in the flight cost of bats and birds (Speakman and Thomas 2003). The cost of flight in birds is estimated at $>80 \%$ of $\dot{\mathrm{V}}_{2(\max )}$ (Guglielmo 2010) and thus represents highintensity exercise.

Although bats are morphologically specialized for flight, the substantial energetic cost of flying introduces specific constraints on foraging strategy, energy storage, and metabolic machinery. The mammalian exercise model predicts that mammals should typically oxidize fatty acids at low exercise intensities and carbohydrates at high exercise intensities (Weber 1992; Brooks 1998; McClelland 2004; Weber 2011). Under this scenario, bats should fuel flight with carbohydrates, as flapping flight is higher intensity compared with terrestrial forms of exercise (Schmidt-Nielsen 1972; Speakman and Thomas 2003). Realistically, however, this is not possible. Given rates of energy expenditure during flight and the low energy density of glycogen $\left(5.3 \mathrm{~kJ} \mathrm{~g}^{-1}\right)$, bats would deplete their glycogen stores within a matter of minutes if they exclusively fueled flight with carbohydrates (Yacoe et al. 1982). It is likely that bats, like birds, fuel endurance flight primarily with fat (McGuire and Guglielmo 2009; Guglielmo 2010, 2018; McGuire et al. 2013a), which is more economical for flight because the high energy density of fat reduces the mass of energy stores flying animals must carry (Jenni and Jenni-Eiermann 1998; McWilliams et al. 2004).

Fat is stored primarily as triglycerides in white adipose tissue, with relatively small amounts of fat stored in lipid droplets in muscle tissue. Under the mammalian exercise model, endurance exercise can be maintained only at the intensity permitted by delivery of fatty acids from adipose tissue into the mitochondria of muscle cells (McGuire and Guglielmo 2009). After being released into circulation, free fatty acids are carried by plasma albumin to the muscle and transported into muscle cells via membrane-bound fatty acid transport proteins (McClelland 2004; Guglielmo 2010; McGuire et al. 2013b). In the cytosol, free fatty acids are transported to the mitochondria by heart-type fatty acid binding protein and converted to fatty acyl-CoAs before being transported to the mitochondria for oxidation (McWilliams et al. 2004; McFarlan et al. 2009; McGuire et al. 2013b).

During exercise, fatty acids are translocated into the mitochondria of muscle cells, where they are catabolized into products that can be used in the Kreb's cycle for energy production. In bat muscle, rates of energy output during flight may be limited by the overall capacity of catabolic enzymes to transport and oxidize fatty acids in the mitochondria. Several studies have demonstrated augmented oxidative enzyme activity in the flight muscle of birds and bats during periods of increased exercise intensity (Guglielmo et al. 2002; McWilliams et al. 2004; McFarlan et al. 2009; Guglielmo 2010; Price et al. 2010; McGuire et al. 2013b). Three enzymes in particular have been shown to be upregulated during migratory periods: carnitine palmitoyl transferase (CPT), 3-hydroxyacyl-CoA dehydrogenase (HOAD), and citrate synthase (CS). CPT is involved in translocating fatty acids from the cytosol across the mitochondrial membrane. HOAD is an enzyme in the $\beta$-oxidation pathway and provides a metric of fatty acid catabolism. CS is an enzyme in the Kreb's cycle and is indicative of overall muscle aerobic capacity. Combined, these three enzymes provide an indication of fatty acid mobilization, catabolism, and oxidation.

In anticipation of energetically demanding life stages, bats, like many animals, accumulate energy stores. Before migration, bats deposit fat to fuel long-distance migratory flights (Voigt et al. 2010, 2012; McGuire et al. 2013a). In situations when fat stores are depleted and requirements for oxidative metabolism exceed rates of fatty acid acquisition from dietary sources, lipogenesis may be upregulated in the liver. Fatty acid synthase (FAS) is an enzyme in the liver that synthesizes fatty acids de novo (Guynn and Veech 1975; Muesing and Porter 1975; Nepokroeff et al. 1975; Ramenofsky 1990) and may be seasonally modulated as for catabolic enzymes. For example, in western sandpipers (Calidris mauri) hepatic FAS activity increases substantially during migration, associated with periods of rapid refueling and fat deposition (Egeler et al. 2000).

While previous studies have examined migration-related changes in lipid metabolism, bats also face varying energetic challenges throughout the summer and during premigratory periods. In the summer, female bats are confronted with the energetic and nutritional costs of reproduction, which include the production and maintenance of fetal, placental, and mammary tissues during gestation and lactation (Gittleman and Thompson 1988). Due to restrictions on body size, small mammals face the challenge of acquiring sufficient energy to satisfy reproductive costs without exceeding available resources from energy stores (Speakman 2008). This may be particularly challenging for bats due to constraints on body mass associated with flight (Oftedal 2000). Bats undergo large increases in body mass during pregnancy, with newborn bats weighing up to $30 \%$ of the maternal postpartum mass, which increases the energetic cost of flight and limits the amount of energy that can be stored before lactation (Kurta and Kunz 1987; Webb et al. 1992; Hughes and Rayner 1993; McLean and Speakman 2000). Lactation is generally considered the most energetically demanding period of the reproductive cycle (Racey and Speakman 1987; Kurta et al. 1989; Kunz et al. 1995; Hood et al. 2006), with lactating females experiencing energy demands two and a half to five times greater than those of nonreproductive counterparts (Oftedal 1984). Bats devote $20 \%-40 \%$ of daily energy expenditure to milk production during lactation (Racey and Speakman 1987) and have to nurse for extended periods of time because juveniles are not weaned until they become volant when reaching nearly adult size (Barclay 1995).

To maintain energy balance and maximize performance in response to variable challenges during the active season (e.g., reproduction and migration), we hypothesized that female bats would flexibly adjust physiological traits related to energy storage and metabolic capacity with changes in energy expenditure. We 
expected to observe changes in body mass on short timescales throughout the active season as bats used and accumulated fat stores in response to costs associated with each life-cycle stage. We also predicted that lipid biosynthetic capacity (FAS activity) in the liver and lipid oxidative capacity (CPT, HOAD, and CS activity) in the pectoral muscle would be elevated in response to increased energy expenditure during lactation. Before fall migration, we expected FAS activity to increase concurrently with premigratory fat deposition and lipid oxidative capacity to increase relative to postlactation as bats prepared to make longdistance migratory flights.

\section{Methods}

\section{Study System}

Brazilian free-tailed bats (Tadarida brasiliensis) are small insectivores in the family Molossidae that are abundant throughout the Americas at latitudes below $40^{\circ} \mathrm{N}$ (Hall 1981; McCracken et al. 2018). The subspecies T. brasiliensis mexicana occurs in Mexico and the southwestern United States and makes long-distance seasonal migrations (Villa and Cockrum 1962; Fleming and Eby 2003; Russell et al. 2005). It is estimated that $>100$ million bats migrate annually from overwintering sites in central Mexico to the south-central United States, where they form large summer colonies in caves and bridges across the region (Wahl 1993). Migration is female biased, with cave populations consisting almost entirely of females and their young during the summer (Lee and McCracken 2005). Mating occurs in transitional roosts in Mexico during the northward migration (McCracken and Wilkinson 2000) or following arrival at summer sites in late March and early April (Keeley and Keeley 2004). Females typically give birth to a single pup in mid-June (Davis et al. 1962) and nurse young for 6-7 wk (McCracken and Gustin 1991). After weaning, bats begin to disperse and form smaller colonies away from maternity caves and return to central Mexico starting in September and October (Villa and Cockrum 1962; Russell et al. 2005). By late fall, bats migrating south from the Great Plains region are concentrated from central Texas southward (Glass 1982). In recent years, an increasing number of bats have been overwintering in Texas (Weaver et al. 2015; Stepanian and Wainwright 2018).

Free-tailed bats are specialized for fast continuous flight due to the long pointed shape of their wings, which results in a high aspect ratio and high wing loading (Norberg and Rayner 1987). Tadarida brasiliensis have the fastest recorded flight speed of all bat species (McCracken et al. 2016) and travel up to $50 \mathrm{~km}$ from their roosts on a single foraging flight (Davis et al. 1962; Williams et al. 1973). Unsurprisingly, the flight muscles of T. brasiliensis are comprised predominantly of fast-twitch oxidative muscle fibers (Foehring and Hermanson 1984), which represents an adaptation for the high metabolic cost of prolonged flight.

\section{Study Site and Sample Collection}

We captured adult female bats using hand nets and mist nets at Frio Cave in Uvalde County, Texas, from April to November 2016. Estimates of summer T. brasiliensis populations at Frio
Cave range from 1 to 10 million individuals (Betke et al. 2008). We identified individuals in late pregnancy by the presence of a palpable embryo, and we identified lactating bats by manually expressing milk from the mammary glands. Subadults were identified by the degree of ossification of the metacarpal-phalanges joint (Brunet-Rossinni and Wilkinson 2009). All subadults were released on capture.

Tissue sampling took place approximately monthly over the course of the study period and was timed to correspond with early pregnancy in April, late pregnancy in May, late lactation in July, postlactation in August, premigration in September, and early migration in November. Animals were not collected during early lactation or midlactation, when females would have had dependent young. All bats were euthanized by cervical dislocation under isoflurane anesthesia, and samples of pectoral muscle and liver were quickly dissected and stored over liquid $\mathrm{N}_{2}$ until analysis. All animal collection and experimental protocols were approved by the Texas Tech University Animal Care and Use Committee (protocol 16014-05) and conducted under a permit from the Texas Parks and Wildlife Department (permit SPR-0416115).

\section{Preparation of Tissue Homogenates}

Liver and muscle samples were prepared by combining approximately $100 \mathrm{mg}$ of tissue with nine volumes of stabilizing homogenization buffer $\left(20 \mathrm{mM} \mathrm{NA}_{2} \mathrm{HPO}_{4}, 0.5 \mathrm{mM}\right.$ EDTA, $0.2 \%$ defatted bovine serum albumin, $50 \%$ glycerol, and $0.1 \%$ Triton X-100, plus $50 \mu \mathrm{g} \mathrm{mL}^{-1}$ aprotinin for muscle homogenate) and homogenized using a handheld homogenizer (Benchmark D1000; Benchmark Scientific, Edison, NJ) for $3 \times 10 \mathrm{~s}$, keeping samples on ice for at least $30 \mathrm{~s}$ between intervals. We sonicated the homogenates $(\mathrm{W}-225 \mathrm{R}$ with $\mathrm{H}-1$ probe; Heat Systems-Ultrasonics, Plainview, NY) for $3 \times 10$ s to lyse cellular and mitochondrial membranes and then centrifuged the samples at $12,000 \mathrm{~g}$ at $4^{\circ} \mathrm{C}$ for $10 \mathrm{~min}$. Supernatant fractions were stored at $-80^{\circ} \mathrm{C}$ until analysis.

\section{Enzyme Assays}

All enzyme assays were carried out in triplicate at $39^{\circ} \mathrm{C}$ in $96-$ well microplates and read using a PowerWave microplate spectrophotometer (BioTek, Winooski, VT). Assays for CS, HOAD, and CPT were adapted from methods in McGuire et al. (2013a), and the assay for FAS was adapted from methods in Egeler et al. (2000). CPT was assayed in $50 \mathrm{mM}$ Tris buffer ( $\mathrm{pH}$ 8.0) with $5 \mathrm{mM}$ carnitine, $0.75 \mathrm{mM}$ DTNB, $0.35 \mathrm{mM}$ palmitoyl CoA, and $4 \mu \mathrm{L}$ of homogenate diluted $1: 40$. HOAD was assayed in $50 \mathrm{mM}$ imidazole buffer ( $\mathrm{pH} 7.4$ ) with $0.2 \mathrm{mM}$ NADH, 1 mM EDTA, $0.1 \mathrm{mM}$ acetoacetyl CoA, and $4 \mu \mathrm{L}$ of homogenate diluted $1: 40$. CS was assayed in $50 \mathrm{mM}$ Tris buffer ( $\mathrm{pH} 8.0$ ) with $0.25 \mathrm{mM}$ oxaloacetic acid, $0.75 \mathrm{mM}$ DTNB, $0.3 \mathrm{mM}$ acetyl CoA, and $4 \mu \mathrm{L}$ of homogenate diluted $1: 80$. FAS was assayed in $1 \mathrm{mM}$ EDTA, $0.1 \mathrm{M}$ potassium phosphate, $25 \mu \mathrm{M}$ acetyl CoA, $0.2 \mathrm{mM}$ $\mathrm{NADPH}, 75 \mu \mathrm{M}$ malonyl CoA, and $8 \mu \mathrm{L}$ of homogenate diluted 1:4 in $1 \mathrm{mM}$ DTT, $1 \mathrm{mM}$ EDTA, and $0.1 \mathrm{M}$ potassium 
phosphate and incubated for $10 \mathrm{~min}$ at $39^{\circ} \mathrm{C}$ (Guynn and Veech 1975; Muesing and Porter 1975; Nepokroeff et al. 1975; Egeler et al. 2000).

Absorbance was measured at $39^{\circ} \mathrm{C}$ in 1 -min intervals for a total of $10 \mathrm{~min}$ for all assays. CS and CPT reactions were indicated by the rate of reduction of DTNB by free CoA measured at $412 \mathrm{~nm}$. HOAD and FAS activities were indicated, respectively, by the consumption and production of NADH measured at $314 \mathrm{~nm}$. Maximal enzyme activities were calculated using the following equation: activity $=[(\Delta A \times \mathrm{tV} \times \mathrm{df}) /(\mathrm{sV} \times E \times d)]$, where $\Delta A$ is the slope of absorbance change, $\mathrm{tV}$ is the total reaction volume $(\mu \mathrm{L}), \mathrm{df}$ is the sample dilution factor, $\mathrm{sV}$ is the volume of sample added to the reaction mixture $(\mu \mathrm{L}), E$ is the molar extinction coefficient $\left(\mathrm{mM}^{-1} \mathrm{~cm}^{-1}\right)$, and $d$ is the length of the light path $(\mathrm{cm})$. Light path was measured as the vertical height of the reaction volume in the microplate well. For FAS activity calculations, $\Delta A$ was divided by 14 , as only $1 \mathrm{~mol}$ of fatty acid is produced for every $14 \mathrm{~mol}$ of NADPH consumed.

\section{Data Analysis}

All analyses were conducted in R (ver. 3.4.1; R Development Core Team 2017). Relationships between body mass, enzyme activities, and sampling period were analyzed using general linear models and Tukey tests for post hoc pairwise comparisons. Starting with fully saturated models, we sequentially removed the least significant term and reevaluated the model until only significant terms remained. CS and HOAD activities exhibited heteroscedasticity among sampling periods and were thus analyzed using generalized least squares models with unequal variance structures using the gls function with the varIdent variance structure from the nlme R package (Pinheiro et al. 2017). This method takes differences in residual variation among groups into account by including variance as a covariate in the models (Zuur et al. 2009). Models were graphically validated by plotting the standardized residuals and checking for homogeneity of variance among groups.

\section{Results}

Body mass of adult females varied in relation to sampling period ( $n=58 ; F_{5,52}=29.45, P<0.001$; fig. 1 ). Predictably, body mass increased during pregnancy with an observed increase of $20 \%$ (2.4 g) between April and May $(P=0.002)$. Body mass decreased following parturition $(2.0 \mathrm{~g} ; P=0.001)$ and continued to decrease through lactation (1.6 g; $P=0.001)$. Body mass then increased between the end of lactation and the presumed beginning of fall migration by $45 \%$ (5.0 g; $P<0.001)$.

CS activity varied with sampling period $\left(n=58 ; F_{5,52}=\right.$ 7.11, $P<0.001$; fig. $2 a$ ), increasing by $24 \%$ from early pregnancy in April to late lactation in July $(P<0.001)$, and this elevated activity was consistent for the duration of the study period. HOAD activity also varied among sampling periods $\left(n=58 ; F_{5,52}=4.15, P=0.003\right.$; fig. $2 b$ ), increasing by $67 \%$ from early pregnancy to lactation $(P=0.02)$. CPT activity exhibited temporal variation similar to $\mathrm{CS}$ and $\operatorname{HOAD}(n=58$; $F_{5,52}=4.58, P=0.001$; fig. $2 c$ ), with the highest mean activity observed postlactation ( $66 \%$ increase from early pregnancy; $P=0.004)$. For all three catabolic enzymes, there was no change in activity between lactation (for CS and HOAD) or postlactation (for CPT) and migration. There was no relationship between body mass and enzyme activity for $\operatorname{CS}\left(F_{1,56}=0.15, P=0.7\right)$ or $\operatorname{HOAD}\left(F_{1,56}=0.18, P=0.7\right)$, but body mass was negatively related to CPT activity $\left(F_{1,56}=5.17, P=0.03\right)$.

Variation in mean FAS activity among sampling periods approached significance $\left(n=56 ; F_{5,49}=2.25, P=0.06\right.$; fig. 3 ). However, FAS activity was negatively correlated with body

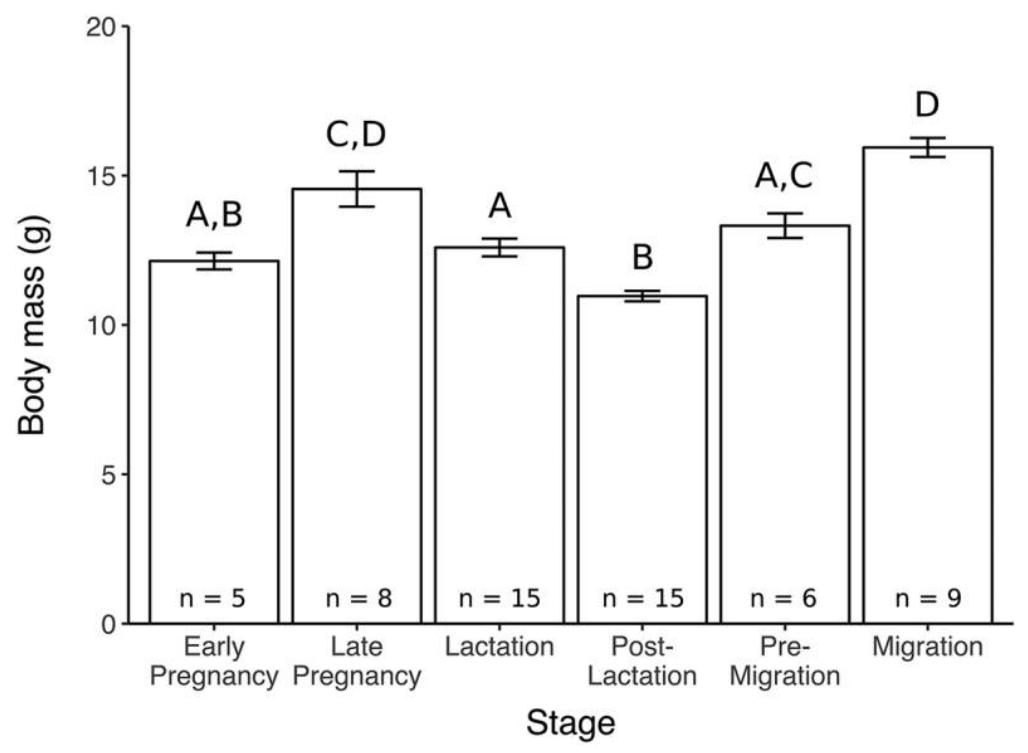

Figure 1. Body mass in Brazilian free-tailed bats during early pregnancy, late pregnancy, lactation, postlactation, premigration, and early fall migration. Bars indicate mean \pm SE. Groups with the same letter were not significantly different. 


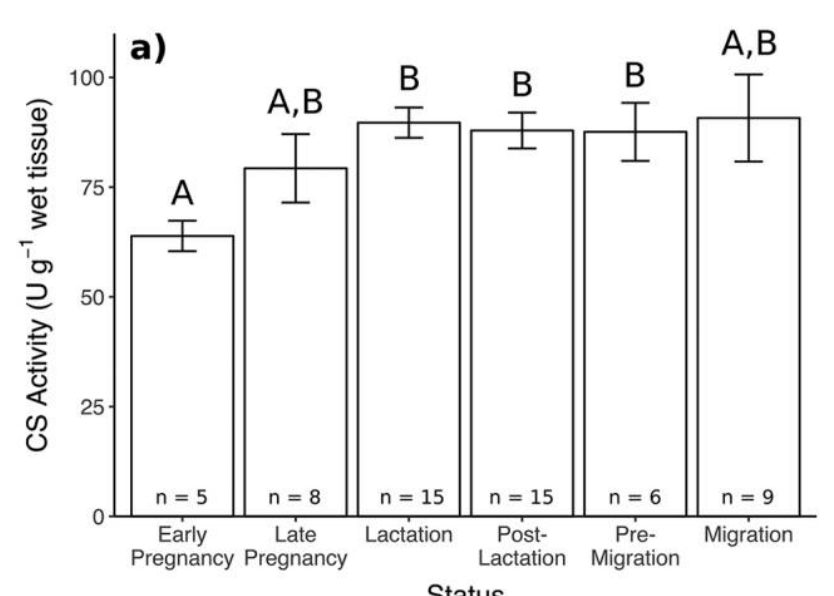

Status
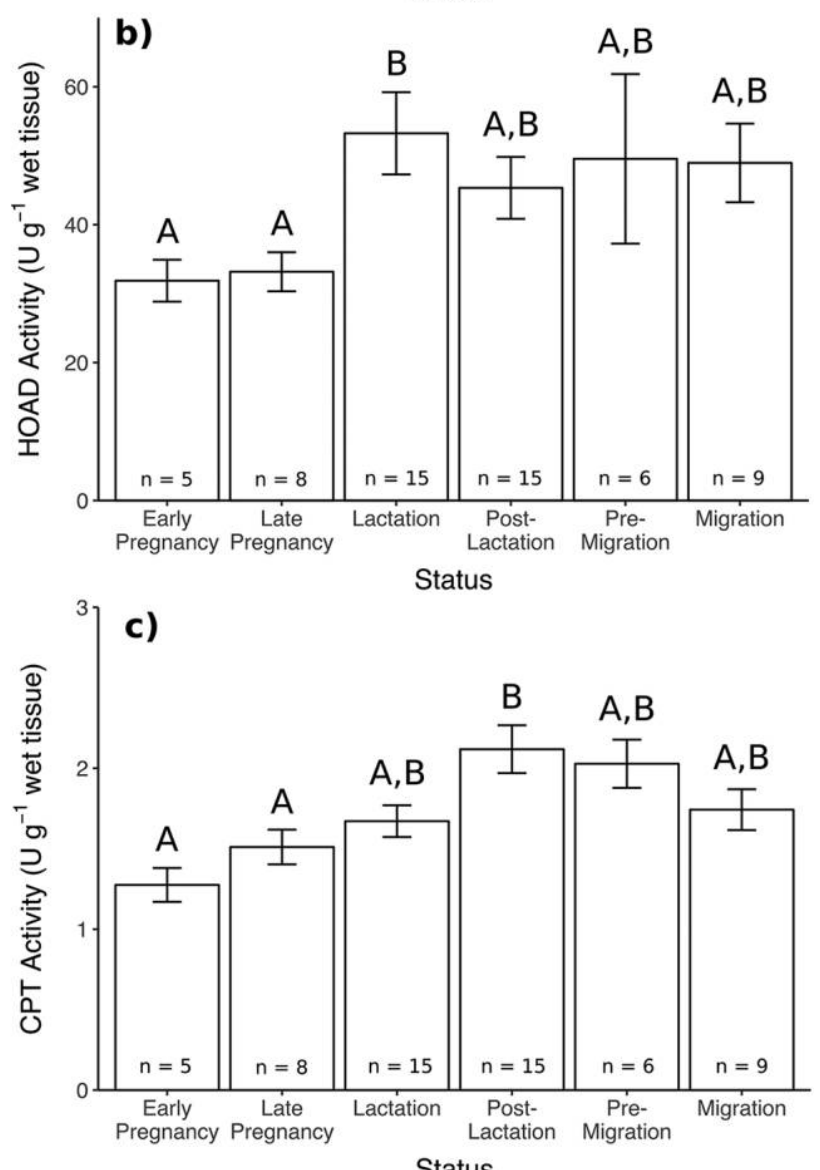

Figure 2. Seasonal changes in enzyme activities in Brazilian free-tailed bats were observed for citrate synthase (CS; a), 3-hydroxyacyl-CoA dehydrogenase (HOAD; $b$ ), and carnitine palmitoyl transferase (CPT; $c$ ) during early pregnancy, late pregnancy, lactation, postlactation, premigration, and early fall migration. These enzymes indicate aerobic capacity, $\beta$-oxidation, and translocation of fatty acids into mitochondria, respectively. Bars indicate mean \pm SE. Groups with the same letter were not significantly different.

mass across all groups $\left(F_{1,54}=12.53, P<0.001\right)$. This relationship remained significant after removing pregnant females, for which body mass may not reflect body condition, from the analysis $\left(F_{41,1}=11.5, P=0.002\right.$; fig. 4$)$.

\section{Discussion}

The bats in our study exhibited substantial variation in body mass throughout the active season (fig. 1) due to the growth and loss of fetal tissue as well as assumed changes in the quantity of stored fat. Although the relative contributions of fat and lean tissue mass changes are unknown, a separate study of the same individual bats included in our study found that lean mass change was minimal relative to overall body mass changes, suggesting that variation in body mass following birth was primarily due to changes in fat mass (Sommers 2017).

Between late lactation and early postlactation we observed a $13 \%$ loss of body mass in females, which is consistent with several previous observations of fat depletion in lactating bats and suggests that fat stores are mobilized to maintain milk production when nutrient intake is insufficient (Reynolds and Kunz 2000; Hood et al. 2006). As with other insectivorous bat species, declines in fat mass during lactation suggest that the cost of lactation in Tadarida brasiliensis may exceed what is available from food consumption and necessitate at least partial reliance on energy stores. While subsidies from maternal fat stores for fueling lactation may be minimal compared with energy allocated to milk production from daily food intake (Speakman and Racey 1987; Kurta et al. 1989; McLean and Speakman 1999), the accumulation of daily contributions across the duration of lactation could lead to the body mass declines we observed in this study.

Energy requirement is often the main constraint on reproductive performance and output in small mammals due to body size restrictions that limit the amount of energy that can be stored as fat (Bronson 1989; Speakman 2008). To satisfy increased energy demands during reproduction, most small mammals must increase daily food consumption (Thompson 1992; Poppit et al. 1993). Bats have been observed to increase nightly food intake (Barclay 1989; Kunz et al. 1995) and foraging times (Barclay 1989; Rydell 1989; Duvergé et al. 2000; Lee and McCracken 2001) during reproduction, with foraging activity peaking in late lactation (Kunz 1974; Anthony and Kunz 1977; Kurta et al. 1990). Due to the substantial cost of flight, bats expend more than half of their daily energy budgets during reproduction on foraging (Kurta et al. 1989). In summer, weather patterns in south-central Texas are relatively stable, and a variety of energy-dense insects are abundant (Kunz et al. 1995; Lee and McCracken 2005). In the absence of environmental constraints on foraging or limits on prey availability, changes in foraging activity during reproduction should directly reflect changes in energy need.

Regardless of whether animals use stored energy or ingested nutrients to meet demands, increased expenditure may require flexible adjustments in the capacity of the physiological machinery used to assimilate and metabolize energy. This is particularly true if animals operate at or near their metabolic ceiling, the maximal sustained working capacity of an individual (Drent and Dan 1980; Piersma and van Gils 2011). The changes we observed in CS and HOAD activity (fig. $2 a$ and $2 b$, respectively) in the flight muscle of $T$. brasiliensis correspond with 


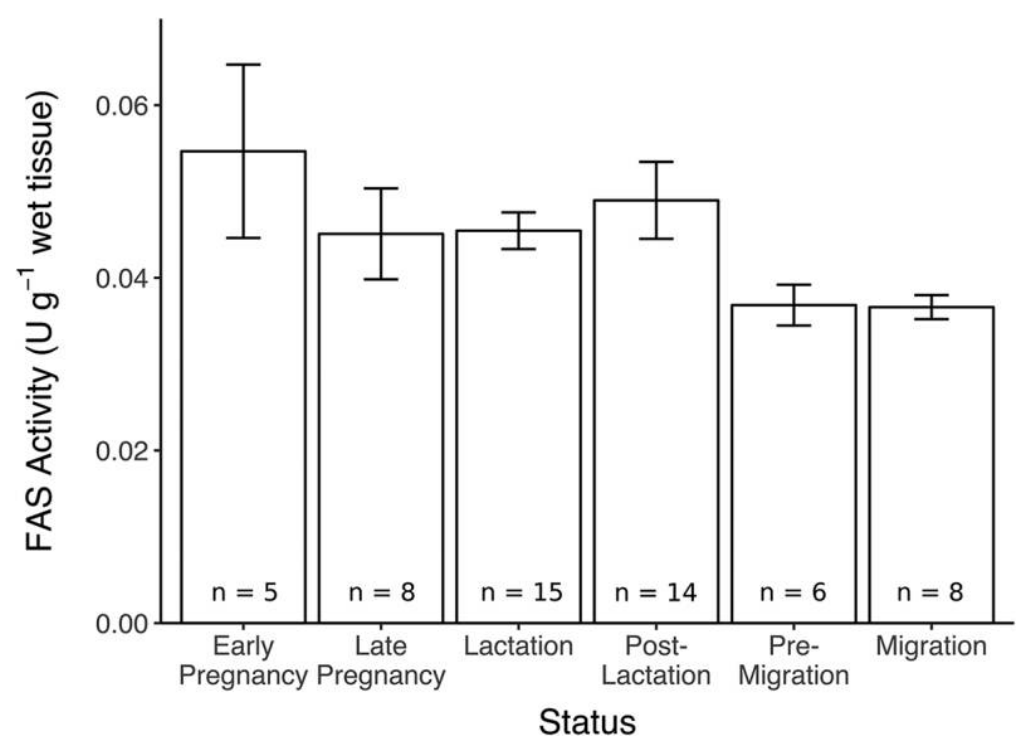

Figure 3. Changes in fatty acid synthase (FAS) activity in Brazilian free-tailed bats during early pregnancy, late pregnancy, lactation, postlactation, premigration, and early fall migration. Bars indicate mean $\pm \mathrm{SE}$.

estimated increases in expenditure on foraging flights during late lactation (Kunz 1974; Anthony and Kunz 1977; Kurta et al. 1989; Kurta et al. 1990), which supports our prediction that lipid oxidative capacity would be elevated in response to increased energy demands. Conversely, CPT activity (fig. 2c) was highest during the postlactation time point, when energy demands should be the lowest, but it is possible that the observed increase in activity was a carryover effect from peak energy demands experienced during late lactation.

We observed a $45 \%$ increase in body mass between the end of lactation and early fall migration (fig. 1), which is consistent with observations of migration-related hyperphagy and fat deposition in this species (O'Shea 1976; Widmaier et al. 1996). Conversely, there were no changes in enzyme activities during this same time period. While many species of migratory birds increase oxidative capacity before migration (Marsh 1981; Zajac et al. 2011), others require endurance flight training to stimulate upregulation of catabolic enzymes (Guglielmo et al. 2002). In this study, we saw no evidence of increased enzyme activity premigration (fig. 2), suggesting that this species does not anticipate migration by elevating its capacity for lipid oxidation. Additionally, we saw no change in enzyme activity during the early migration time point, when individuals were likely migrating and using Frio Cave as a stopover (Krauel et al.2015). It is possible that the individuals sampled for this time point were overwintering residents, but given the size of this population (Betke et al. 2008) compared with estimates of overwintering populations in the area (Stepanian and Wainwright 2018), it is likely that they were either preparing for migration or en route.

Our results suggest that this species, which is an aerial insectivore morphologically and physiologically adapted for fast, continuous flight (Davis et al. 1962; Williams et al. 1973; Foehring and Hermanson 1984; McCracken et al. 2016), may not require additional physiological compensations to adequately satisfy migration-related demands. Tadarida brasiliensis fly $>100 \mathrm{~km}$ a night on regular foraging flights in summer (Davis et al. 1962; Williams et al. 1973), so making nightly long-distance flights to central Mexico during fall migration may not be very challenging, particularly if they forage opportunistically while in flight. These adaptations and differences in ecology may also explain why the absolute activities of CS, CPT, and HOAD observed in this species are lower on average than those observed in migrating birds (Marsh 1981; Lundgren and Kiessling 1985; Guglielmo et al. 2002; McFarlan et al. 2009). Alternatively, if the bats sampled for the early migration time point were in fact summer residents still preparing to leave, it remains possible that changes in oxidative capacity may have occurred after they started actively migrating.

The changes we observed in the activity of lipid oxidative enzymes in the flight muscle over the active season suggest that the energy costs associated with reproduction require increased capacity for conversion of fatty acids into usable energy. However, these pathways rely on the availability of fatty acids from the diet or from adipose stores as well as sufficient capacity for fatty acid uptake from circulation. Migrating birds and bats are known to upregulate fatty acid transport proteins, such as heart-type fatty acid binding protein and plasma-membrane fatty acid binding protein (Guglielmo et al. 2002; McFarlan et al. 2009; McGuire et al. 2013b), to meet requirements for fatty acid transport into the muscle during migratory flight. As bats rely on fatty acids to fly, we predicted that bats would exhibit increased fatty acid synthesis in the liver in response to increased energy expenditure during lactation. Although we observed no change in FAS activity among sampling events (fig. 3 ), we did find a negative correlation between enzyme activity and body mass across all life-cycle stages (fig. 4). These results suggest that bats do not upregulate FAS to cope with short-term energy costs but that 


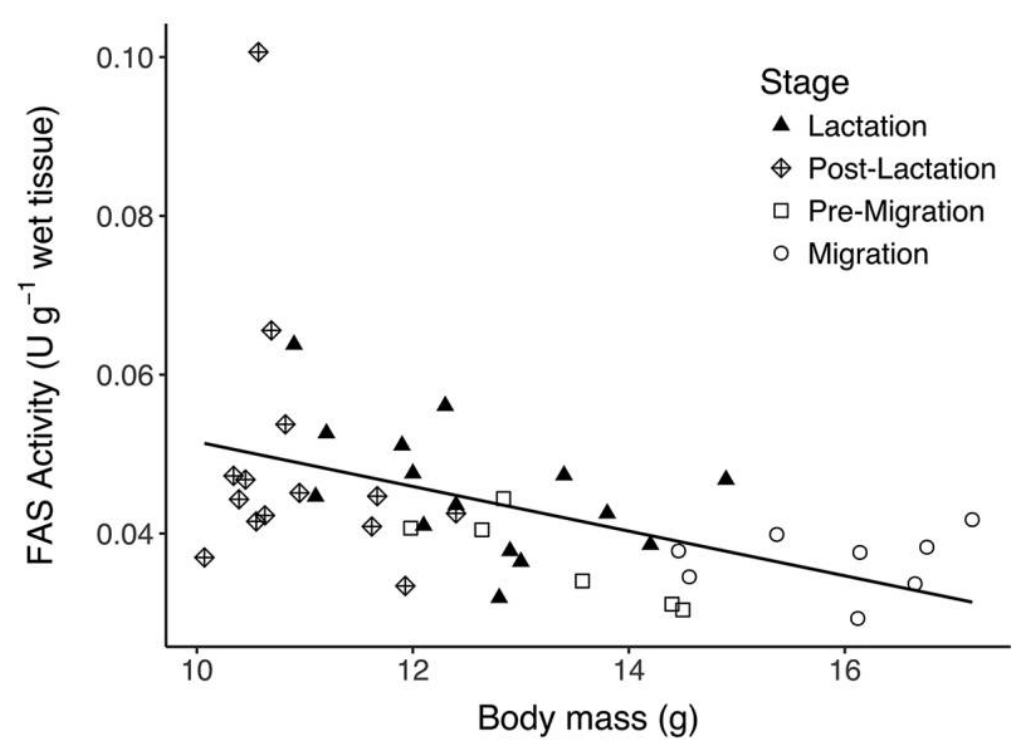

Figure 4. Relationship between body mass and fatty acid synthase (FAS) activity in Brazilian free-tailed bats during the active season $(n=43)$. Pregnant bats were excluded.

bats with less stored fat (i.e., with lower body condition) may rely more on de novo fatty acid synthesis regardless of life-cycle stage. While it is perhaps surprising that we did not see increased FAS activity simultaneous to premigration fattening, bats are known to forage on high-fat migratory moths at this time of year, which may make de novo fatty acid synthesis unnecessary (Krauel et al. 2015, 2018). Furthermore, bats may also increase fuel deposition rate by using torpor during the day. In the absence of any biochemical compensation, reduced daytime energy expenditure leads to increased net fueling rate from the same amount of ingested energy (McGuire and Guglielmo 2009; McGuire et al. 2014).

\section{Conclusion}

Bats fuel flight with lipids, and thus the capacity to oxidize lipids in working tissues should be a limiting step in pathways for aerobic metabolism. Our study demonstrates that bats mobilize stored fat and increase lipid oxidative capacity in flight muscle in late lactation, which reflect estimated increases in daily energy expenditure during reproduction. Additionally, bats that weighed less exhibited increased fatty acid synthesis in the liver, suggesting that bats may compensate for smaller fat stores by relying more heavily on pathways for de novo fatty acid synthesis. In light of these results, we suggest that highly aerobic mammals, which are adapted to regularly maintain extreme levels of energy expenditure, are able to raise the metabolic capacity of working tissues on short timescales in response to need by flexibly adjusting physiological traits that constrain energy output. Whether metabolic capacity in bats and other highly aerobic mammals is more greatly constrained by peripheral factors (e.g., aerobic capacity in the muscle) or by central factors (e.g., assimilation efficiency) is a valuable topic of future research.

\section{Acknowledgments}

We thank Caleb Phillips for helpful discussions and Alex Gerson for assistance with developing laboratory analysis methods and valuable feedback on the manuscript. We also thank Oscar Sandate, Garrett Edwards, Jeff Clerc, Nate Fuller, Craig Tipton, Matthew Fox, Marilyn Mathew, Greg Knox, Macy Madden, and Iroro Tanshi for assistance in the field. We appreciate the helpful feedback provided by two anonymous reviewers. Funding for this study was provided by Texas Tech University, the Natural Science Research Laboratory at the Texas Tech Museum, and the Texas Tech Graduate School.

\section{Literature Cited}

Anthony E.L.P. and T.H. Kunz. 1977. Feeding strategies of the little brown bat, Myotis lucifugus, in southern New Hampshire. Ecology 58:775-786.

Barclay R.M.R. 1989. The effect of reproductive condition on the foraging behavior of female hoary bats, Lasiurus cinereus. Behav Ecol Sociobiol 24:31-37.

. 1995. Does energy or calcium availability constrain reproduction by bats? Symp Zool Soc Lond 67:245-258.

Betke M., D.E. Hirsh, N.C. Makris, G.F. McCracken, M. Procopio, N.I. Hristov, S. Tang, et al. 2008. Thermal imaging reveals significantly smaller Brazilian free-tailed bat colonies than previously estimated. LMammal 89:18-24.

Bronson F. 1989. Mammalian reproductive biology. University of Chicago Press, Chicago.

Brooks G.A. 1998. Mammalian fuel utilization during sustained exercise. Comp Biochem Physiol B 120:89-107.

Brunet-Rossinni A.K. and G.S. Wilkinson. 2009. Methods for age estimation and the study of senescence in bats. Pp. 315325 in T.H. Kunz and S. Parsons, eds. Ecological and be- 
havioral methods for the study of bats. Johns Hopkins University Press, Baltimore.

Buehler D.M. and T. Piersma. 2008. Travelling on a budget: predictions and ecological evidence for bottlenecks in the annual cycle of long-distance migrants. Philos Trans R Soc Lond B 363:247-266.

Davis R.B., C.F. Herreid, and H.L. Short. 1962. Mexican freetailed bats in Texas. Ecol Monogr 32:311-346.

Drent R.H. and S. Daan. 1980. The prudent parent: energetic adjustments in avian breeding. Ardea 68:225-252.

Duvergé P.L., G. Jones, J. Rydell, and R.D. Ransome. 2000. Functional significance of emergence timing in bats. Ecography 23:32-40.

Egeler O., T.D. Williams, and C.G. Guglielmo. 2000. Modulation of lipogenic enzymes, fatty acid synthase and $\Delta 9$ desaturase, in relation to migration in the western sandpiper (Calidris mauri). L Comp Physiol B 170:169-174.

Fleming T.H. and P. Eby. 2003. Ecology of bat migration. Pp. 156-208 in T.H. Kunz and M.B. Fenton, eds. Bat ecology. University of Chicago Press, Chicago.

Foehring R.C. and J.W. Hermanson. 1984. Morphology and histochemistry of flight muscles in free-tailed bats, Tadarida brasiliensis. LMammal 65:388-394.

Gittleman J.L. and S.D. Thompson. 1988. Energy allocation in mammalian reproduction. Am Zool 28:863-875.

Garland T. 2014. Trade-offs. Curr Biol 24:R60-R61.

Glass B.P. 1982. Seasonal movements of Mexican free-tailed bats Tadarida brasiliensis mexicana banded in the Great Plains. Southwest Nat 27:127-133.

Guglielmo C.G. 2010. Move that fatty acid: fuel selection and transport in migratory birds and bats. Integr Comp Biol 50: 336-345.

- 2018. Obese super athletes: fat-fueled migration in birds and bats. L Exp Biol 221:ieb165753.

Guglielmo C.G., N.H. Haunerland, P.W. Hochachka, and T.D. Williams. 2002. Seasonal dynamics of flight muscle fatty acid binding protein and catabolic enzymes in a migratory shorebird. Am I Physiol Regul Integr Comp Physiol 282: R1405-R1413.

Guynn R.W. and R.L. Veech. 1975. Measurement of malonyl coenzyme A. Methods Enzymol 35:312-315.

Hall E. 1981. The mammals of North America. 2nd ed. Wiley, New York.

Hammond K.A. and J. Diamond. 1997. Maximal sustained energy budgets in humans and animals. Nature 386:457-462.

Hood W.R., O.T. Oftedal, and T.H. Kunz. 2006. Variation in body composition of female big brown bats (Eptesicus fuscus) during lactation. L Comp Physiol B 176:807-819.

Hughes P. and J.M.V. Rayner. 1993. The flight of pipistrelle bats Pipistrellus pipistrellus during pregnancy and lactation. Z Zool (Lond) 230:541-555.

Jenni L. and S. Jenni-Eiermann. 1998. Fuel supply and metabolic constraints in migrating birds. LAvian Biol 29:521-528.

Karasov W.H. 1986. Energetics, physiology, and vertebrate ecology. Trends Ecol Evol 1:101-104.
Keeley A.T.H. and B.W. Keeley. 2004. The mating system of Tadarida brasiliensis (Chiroptera: Molossidae) in a large highway bridge colony. L Mammal 85:113-119.

Krauel J.J., J.K. Westbrook, and G.F. McCracken. 2015. Weatherdriven dynamics in a dual-migrant system: moths and bats. IAnim Ecol 84:604-614.

Krauel J.J., J.M. Ratcliffe, J.K. Westbrook, and G. McCracken. 2018. Brazilian free-tailed bats (Tadarida brasiliensis) adjust foraging behavior in response to migratory moths. Can L Zool 96:513-520.

Kunz T.H. 1974. Feeding ecology of a temperate insectivorous bat (Myotis velifer). Ecology 55:693-711.

Kunz T.H., J.O. Whitaker Jr., and M.D. Wadanoli. 1995. Dietary energetics of the insectivorous Mexican free-tailed bat ( $\mathrm{Ta}$ darida brasiliensis) during pregnancy and lactation. Oecologia 101:407-415.

Kurta A., G.P. Bell, K.A. Nagy, and T.H. Kunz. 1989. Energetics of pregnancy and lactation in free-ranging little brown bats (Myotis lucifugus). Physiol Zool 62:804-818.

Kurta A. and T.H. Kunz. 1987. Size of bats at birth and maternal investment during pregnancy. Symp Zool Soc Lond 57:79106.

Kurta A., T.H. Kunz, and K.A. Nagy. 1990. Energetics and water flux of free-ranging big brown bats (Eptesicus fuscus) during pregnancy and lactation. L Mammal 71:59-65.

Lee Y.-F. and G.F. McCracken. 2001. Timing and variation in the emergence and return of Mexican free-tailed bats, Tadarida brasiliensis mexicana. Zool Stud 40:309-316.

_ 2005. Dietary variation of Brazilian free-tailed bats links to migratory populations of pest insects. L Mammal 86: 67-76.

Levins R. 1968. Evolution in changing environments: some theoretical explorations. Princeton University Press, Princeton, NJ.

Lundgren B.O. and K.H. Kiessling. 1985. Seasonal variation in catabolic enzyme activities in breast muscle of some migratory birds. Oecologia 66:468-471.

Marsh R.L. 1981. Catabolic enzyme activities in relation to premigratory fattening and muscle hypertrophy in the gray catbird (Dumetella carolinensis). L Comp Physiol B 141: 417-423.

McClelland G.B. 2004. Fat to the fire: the regulation of lipid oxidation with exercise and environmental stress. Comp Biochem Phvsiol B 139:443-460.

McCracken G.F., R.F. Bernard, M. Gamba-Rios, R. Wolfe, J.J. Krauel, D.N. Jones, A.L. Russell, et al. 2018. Rapid range expansion of the Brazilian free-tailed bat in the southeastern United States, 2008-2016. L Mammal 99:312-320.

McCracken G.F and M.K. Gustin. 1991. Nursing behavior in Mexican free-tailed bat maternity colonies. Ethology 89: 305-321.

McCracken G.F., K. Safi, T.H. Kunz, D.K.N. Dechmann, S.M. Swartz, and M. Wikelski. 2016. Airplane tracking documents the fastest flight speeds recorded for bats. $\underline{\mathrm{R} \text { Soc Open Sci 3: }}$ 160398 . 
McCracken G.F. and G.S. Wilkinson. 2000. Bat mating systems. Pp. 321-362 in E. Crichton and P. Krutzsch, eds. Reproductive biology of bats. Academic Press, San Diego.

McFarlan J.T., A. Bonen, and C.G. Guglielmo. 2009. Seasonal upregulation of fatty acid transporters in flight muscles of migratory white-throated sparrows (Zonotrichia albicollis). LExp Biol 212:2934-2940.

McGuire L.P., M.B. Fenton, and C.G. Guglielmo. 2013a. Phenotypic flexibility in migrating bats: seasonal variation in body composition, organ sizes and fatty acid profiles. LExp Biol 216:800-808.

- 2013b. Seasonal upregulation of catabolic enzymes and fatty acid transporters in the flight muscle of migrating hoary bats, Lasiurus cinereus. Comp Biochem Phvsiol B 165:138-143.

McGuire L.P. and C.G. Guglielmo. 2009. What can birds tell us about the migration physiology of bats? L Mammal 90:12901297.

McGuire L.P., K.A. Jonasson, and C.G. Guglielmo. 2014. Bats on a budget: torpor-assisted migration saves time and energy. PLOS ONE 9:e115724.

McLean J.A. and J.R. Speakman. 1999. Energy budgets of lactating and non-reproductive brown long-eared bats (Plecotus auritus) suggest females use compensation in lactation. Funct Ecol 13:360-372.

. 2000. Morphological changes during postnatal growth and reproduction in the brown long-eared bat Plecotus auritus: implications for wing loading and predicted flight performance. LNat Hist 34:773-791.

McWilliams S.R., C. Guglielmo, B. Pierce, and M. Klaassen. 2004. Flying, fasting, and feeding in birds during migration: a nutritional and physiological ecology perspective. L Avian Biol 35:377-393.

Muesing R.A. and J.W. Porter. 1975. Fatty acid synthase from pigeon liver. Methods Enzymol 35:45-59.

Nepokroeff C.M., M.R. Lakshmanan, and J.W. Porter. 1975. Fatty acid synthase from rat liver. Methods Enzymol 35:3744.

Norberg U.M. and J.M.V. Rayner. 1987. Ecological morphology and flight in bats (mammalia; chiroptera): wing adaptations, flight performance, foraging strategy and echolocation. Philos Trans R Soc Lond B 316:335-427.

Oftedal O.T. 1984. Milk composition, milk yield and energy output at peak lactation: a comparative review. Symp Zool Soc Lond 51:33-85.

. 2000. Use of maternal reserves as a lactation strategy in large mammals. Proc Nutr Soc 59:99-106.

O'Shea T.J. 1976. Fat content in migratory central Arizona Brazilian free-tailed bats, Tadarida brasiliensis (Molossidae). Southwest Nat 21:321.

Piersma T. and J. Drent. 2003. Phenotypic flexibility and the evolution of organismal design. Trends Ecol Evol 18:228-233.

Piersma T. and J.A. van Gils. 2011. The flexible phenotype: a body-centered integration of ecology, physiology, and behavior. Oxford University Press, New York.
Pinheiro J., D. Bates, S. DebRoy, D. Sarkar, and R.C. Team. 2017. R package 'nlme': linear and nonlinear mixed effects models.

Poppitt S.D., J.R. Speakman, and P.A. Racey. 1993. The energetics of reproduction in the common shrew (Sorex araneus): a comparison of indirect calorimetry and the doubly labeled water method. Physiol Zool 66:964-982.

Price E.R., J.T. McFarlan, and C.G. Guglielmo. 2010. Preparing for migration? the effects of photoperiod and exercise on muscle oxidative enzymes, lipid transporters, and phospholipids in white-crowned sparrows. Phvsiol Biochem Zool 83:252-262.

Racey P.A. and J.R. Speakman. 1987. The energy costs of pregnancy and lactation in heterothermic bats. Symp Zool Soc Lond 57:107-125.

Ramenofsky M. 1990. Fat storage and fat metabolism in relation to migration. Pp. 214-231 in E. Gwinner, ed. Bird migration. Springer, Berlin.

R Development Core Team. 2017. R: a language and environment for statistical computing. R Foundation for Statistical Computing, Vienna. http://www.R-project.org/.

Ricklefs R.E. and M. Wikelski. 2002. The physiology/lifehistory nexus. Trends Ecol Evol 17:462-468.

Reynolds D.S. and T.H. Kunz. 2000. Changes in body composition and postnatal growth in the little brown bat, Myotis lucifigus (Chiroptera: Vespertilionidae). Ecoscience 7:10-17.

Russell A.L., R.A. Medellín, and G.F. McCracken. 2005. Genetic variation and migration in the Mexican free-tailed bat (Tadarida brasiliensis mexicana): population genetics of Tadarida brasiliensis. Mol Ecol 14:2207-2222.

Rydell J. 1989. Feeding activity of the northern bat Eptesicus nilssoni during pregnancy and lactation. Oecologia 80:562-565.

Schmidt-Nielsen K. 1972. Locomotion: energy cost of swimming, flying, and running. Science 177:222-228.

Sommers A.S. 2017. Phenotypic flexibility and energy demand: insectivorous bat response through the summer active season. MS thesis. Texas Tech University, Lubbock.

Speakman J.R. 1999. The cost of living: field metabolic rates of small mammals. Adv Ecol Res 30:177-297.

. 2008. The physiological costs of reproduction in small mammals. Philos Trans R Soc Lond B 363:375-398.

Speakman J.R. and P.A. Racey. 1987. The energetics of pregnancy and lactation in the brown long-eared bat, Plecotus auritus. Pp. 367-393 in M.B. Fenton, P.A. Racey, and J.M.V. Rayner, eds. Recent advances in the study of bats. Cambridge University Press, Cambridge.

Speakman J.R. and D.W. Thomas. 2003. Physiological ecology and energetics of bats. Pp. 430-490 in T.H. Kunz and M.B. Fenton, eds. Bat ecology. University of Chicago Press, Chicago. Stearns S.C. 1989. Trade-offs in life-history evolution. $\underline{\text { Funct }}$ Ecol 3:259-268.

Stepanian P.M. and C.E. Wainwright. 2018. Ongoing changes in migration phenology and winter residency at Bracken Bat Cave. Global Change Biol 24:3266-3275.

Thomas S.P. and R.A. Suthers. 1972. The physiology and energetics of bat flight. J Exp Biol 57:317-335. 
Thompson S. 1992. Gestation and lactation in small mammals: basal metabolic rate and the limits to energy use. Pp. 213-259 in T.E. Tomasi and T.H. Horton, eds. Mammalian energetics: interdisciplinary views of metabolism and reproduction. Cornell University Press, Ithaca, NY.

Villa R.B and E.L. Cockrum. 1962. Migration in the guano bat Tadaridabrasiliensis mexicana. L Mammal 43:43-64.

Voigt C.C., K. Sörgel, and D.K.N. Dechmann. 2010. Refueling while flying: foraging bats combust food rapidly and directly to power flight. Ecology 91:2908-2917.

Voigt C.C., K. Sörgel, J. Šuba, O. Keišs, and G. Pētersons. 2012. The insectivorous bat Pipistrellus nathusii uses a mixed-fuel strategy to power autumn migration. Proc R Soc B 279: 3772-3778.

Wahl R. 1993. Important Mexican free-tailed bat colonies in Texas. Pp. 47-50 in J.R. Jorden and R.K. Obele, eds. Proceedings of the 1989 National Cave Management Symposium. Texas Cave Management Association, Austin, TX.

Weaver S.P., T.R. Simpson, J.T. Baccus, and F.W. Weckerly. 2015. Baseline population estimates and microclimate data for newly established overwintering Brazilian free-tailed bat colonies in central Texas. Southwest Nat 60:151-157.

Webb P.I., J.R. Speakman, and P.A. Racey. 1992. Inter- and intra-individual variation in wing loading and body mass in female pipistrelle bats: theoretical implications for flight performance. L Zool (Lond) 228:669-673.

Weber J.-M. 1992. Pathways for oxidative fuel provision to working muscles: ecological consequences of maximal supply limitations. Experientia 48:557-564.
2011. Metabolic fuels: regulating fluxes to select mix. LExp Biol 214:286-294.

Weiner J. 1992. Physiological limits to sustainable energy budgets in birds and mammals: ecological implications. Trends Ecol Evol 7:384-388.

Widmaier E.P., E.R. Gornstein, J.L. Hennessey, J.M. Bloss, J.A. Greenberg, and T.H. Kunz. 1996. High plasma cholesterol, but low triglycerides and plaque free arteries, in Mexican free-tailed bats. Am I Physiol Regul Integr Comp Physiol 271:R1101-R1106.

Williams T.C., L.C. Ireland, and J.M. Williams. 1973. High altitude flights of the free-tailed bat, Tadarida brasiliensis, observed with radar. L Mammal 54:807-821.

Yacoe M.E., J.W. Cummings, P. Myers, and G.K. Creighton. 1982. Muscle enzyme profile, diet, and flight in South American bats. Am I Physiol Regul Integr Comp Physiol 242:189194.

Zajac D.M., D.J. Cerasale, S. Landman, and C.G. Guglielmo. 2011. Behavioral and physiological effects of photoperiodinduced migratory state and leptin on Zonotrichia albicollis. II. Effects on fatty acid metabolism. Gen Comp Endocrinol 174:269-275.

Zera A.J. and L.G. Harshman. 2001. The physiology of lifehistory trade-offs in animals. Annu Rev Ecol Evol Syst 32: 95-126.

Zuur A.F., E.N. Ieno, N.J. Walker, A.A. Saveliev, and G.M. Smith. 2009. Dealing with heterogeneity. Pp. 71-100 in M. Gail, K. Krickeberg, J.M. Samet, and A. Tsiatis, eds. Mixed effects models and extensions in ecology with R. Springer, New York. 